\title{
EFFECT OF CARBON BLACK ON THERMAL, MECHANICAL AND ELECTROCONDUCTIVE PROPERTIES OF MATER-BI ${ }^{\circledR}$ MATRIX
}

\author{
KAROL LELUK, JOANNA LUDWICZAK, STANISŁAW FRĄCKOWIAK and \\ ANDRZEJ IWAŃCZUK \\ Faculty of Environmental Engineering, Wroctaw University of Science and Technology, \\ 27, Wybrzeże Wyspiańskiego Str., 50-370 Wrocław, Poland \\ ¿orresponding author: Karol Leluk, karol.leluk@pwr.edu.pl
}

Received September 30, 2019

This paper evaluates the effects of carbon black incorporation on the mechanical and electroconductive properties of biodegradable materials. Biodegradable composites based on Mater-Bi ${ }^{\circledR}$ (MB) filled with 1, 2 or 4 wt $\%$ carbon black (CB) were prepared by melt mixing. Mater- $\mathrm{Bi}^{\circledR}$ is a commercial bio-plastic extensively used in food packaging applications. The thermal, mechanical and electrical properties of the biodegradable matrix and its composites were investigated. The electroconductive properties of the prepared materials were tested to determine the percolation threshold and dielectric relaxation.

Keywords: Mater-Bi ${ }^{\circledR}$, carbon black, thermal, mechanical and electroconductive properties

\section{INTRODUCTION}

Most known polymers have excellent dielectric properties. However, a certain level of electrical conductivity is required for some applications related to antistatic, semiconductor and electromagnetic interference phenomena. For this purpose, electroconductive matrices (polyaniline and polypyrrole) $)^{1-4}$ or the addition of electroconductive fillers are most often used. Carbonaceous particles with various types of structure, including carbon black (CB), ${ }^{5-11}$ carbon nanotubes $(\mathrm{CNTs}),{ }^{12-14}$ carbon fibers $(\mathrm{CF})^{15-16}$ and graphene, ${ }^{17-19}$ are used to produce electrically conductive materials. The final properties of such composites depend not only on the dispersion and concentration of the filler, but also on the structure of the particles.

The most commonly used conductive filler for polymers is carbon black - it is designed to increase conductivity, which is often used in packaging to discharge electrical charge. An important parameter is the critical content of the filler, known as the percolation threshold, which shows the minimum amount of filler to increase the conductivity of the composite. The value of the percolation threshold should be as low as possible to preserve the mechanical properties of the composites, minimize processing problems and reduce the final cost of the materials. ${ }^{20}$

Mater- $\mathrm{Bi}^{\circledR}(\mathrm{MB})$ is a group of biodegradable materials developed from natural agricultural products produced by the Italian concern Novamont. These materials are based on thermoplastic starch, which is mixed or grafted with biodegradable polyesters from vegetable oil to increase the flexibility and moisture resistance of the obtained material. MB is used as packaging material for the production of packaging films, thermoformed trays and containers, foamed mouldings and foamed material for filling free space in transport packaging, as well as for the production of bags for biodegradable waste for composting. MB degradation occurs after 80 days. $21-22$

The purpose of this work has been to develop biodegradable composites based on a Mater- $\mathrm{Bi}^{\circledR}$ matrix, with the addition of electrically conductive filler with different contents. Thermal, mechanical and electrical conductivity as well as dielectric relaxation tests will determine the usability of the developed polymer composites for electrical applications. 


\section{EXPERIMENTAL \\ Materials}

The thermoplastic biopolymer matrix used in this work is a starch-based biopolymer Mater-Bi ${ }^{\circledR}$ EF51L, supplied by Novamont (Italy). Carbon Black (Ketjenblack EC-300J, Akzo Nobel Polymer Chemicals) was used as filler.

\section{Preparation of samples}

The polymer matrix was blended with $\mathrm{CB}(1,2,4$ $\mathrm{wt} \%)$. All the materials were plasticized and blended in a Haake PolyDrive mixer (temperature of $190^{\circ} \mathrm{C}$, rotor speed of $60 \mathrm{rpm}$, for $6 \mathrm{~min}$ ).

\section{Methods}

\section{Thermal properties}

Differential scanning calorimetry (DSC Q20, TA Instruments, USA) was used to investigate the thermal properties, following ISO 11357-5 standard. The thermal ramp was from $40{ }^{\circ} \mathrm{C}$ up to $200{ }^{\circ} \mathrm{C}$, at the rate of $10{ }^{\circ} \mathrm{C} \mathrm{min}^{-1}$ under nitrogen flow. The cooling rate was set to $-5^{\circ} \mathrm{C} \min ^{-1}$.

\section{Mechanical properties}

Tensile properties were tested at a speed of 10 $\mathrm{mm} / \mathrm{min}$ by using a LLOYD LR10K machine (Lloyd Instruments Ltd., UK).

\section{Resistivity measurements}

Samples were prepared by press moulding in the form of plates and, for minimizing the contact resistance, gold electrodes were vapor-deposited on each sample. The current flow was measured using a Keithley 6512 electrometer from Keithley Instruments, while the voltage supply was a High Voltage Power Supply GPR-30H100 (GW Instek).

\section{Dielectric relaxation measurements}

Dielectric relaxation measurements were performed on RLC Bridge HP4284A, 4-electrode system. Samples were formed as pellets, cut out from previously press moulded plates, with a diameter of $12.85 \mathrm{~mm}$ and thickness of $0.30 \mathrm{~mm}$. The thickness of the reference sample $\left(\right.$ Teflon $^{\circledR}$ ), used for determining the dissipation capacitance, was $1.46 \mathrm{~mm}$ (the diameter remained unchanged).

The materials, in the form of pellets, were attached to the instrument without any further treatment. No metal layer (e.g.: silver paste or cuprum foil) was placed onto its surface prior to the experiment. The samples were tightly held within the measuring device by a spring lock mechanism. All the measurements were repeated at least twice (each time on a different pellet) for the same composite material. The temperature and relative humidity remained unchanged during the whole experiment $\left(29^{\circ} \mathrm{C},+/-1^{\circ} \mathrm{C}, 38 \% \mathrm{RH}\right.$, $+/-2 \% \mathrm{RH})$.

\section{RESULTS AND DISCUSSION}

Thermal properties

According to the information provided by the producer, MaterBi is a material based on thermoplastic starch, which is mixed or grafted with biodegradable polyesters. ${ }^{21}$ During the DSC measurements, the glass transition temperatures $T g=-27.9$ and $T g_{2}=63{ }^{\circ} \mathrm{C}$ for the MB matrix were noted (Table 1). Similarly, DSC thermograms showed two temperature transitions related to the melting process $(\mathrm{Tm}=122.6$ and $\mathrm{Tm}_{2}=166.7^{\circ} \mathrm{C}$ ). Double peaks $\mathrm{Tg}$ and $\mathrm{Tm}$ can be derived for thermoplastic starch and polylactide (PLA), respectively. The cold crystallization temperature $T c c\left(107.8^{\circ} \mathrm{C}\right)$ during heating and the crystallization temperature $T c\left(66.6{ }^{\circ} \mathrm{C}\right)$ during cooling were also recorded. The addition of 1,2 or $4 \% \mathrm{CB}$ did not affect significantly the $T g$ and $\mathrm{Tg}_{2}$ values. After the addition of $\mathrm{CB}$, there was a slight decrease in $T c c$ and a significant increase in Tc (up to about $20^{\circ} \mathrm{C}$ with $1 \%$ addition; and $2{ }^{\circ} \mathrm{C}$ with $4 \%$ CB addition). A slight change in $\mathrm{Tm}$ and $\mathrm{Tm}_{2}$ was also observed for the composites, an increase in melting temperature by approximately 2-3 ${ }^{\circ} \mathrm{C}$ was obtained. Therefore, a small amount of $\mathrm{CB}$ affects the formation of crystallites and their melting process in the composites based on MB. This means that carbon black acts as a nucleating agent in the polymer matrix, which is a known phenomenon, as described in earlier studies. $^{23-25}$

\section{Mechanical properties}

The mechanical properties, such as Young's modulus, tensile strength and elongation at break, of the composite materials were evaluated. The obtained data confirm that the addition of $1 \mathrm{wt} \%$ $\mathrm{CB}$ to the polymer matrix results in a visible decrease in the mechanical properties of the composite. ${ }^{26}$

The material becomes stiffer (increasing Young's modulus, Fig. 1) and less elastic (decreasing tensile strength, along with decreasing elongation at break, Figs. 2 and 3). This is mainly connected to CB particles blocking the polymer orientation during the elongation process.

\section{Resistivity measurements}

From the obtained results, one can observe that the percolation threshold for the composites containing carbon black is below $1 \mathrm{wt} \%$ (Table 2). Such low percolation threshold is related to 
the tendency of carbon black to form complex fractal structures, which, in turn, promote the generation of electrically conductive pathways in the polymer matrix.

Table 1

Thermal properties of $\mathrm{MB}$ and $\mathrm{MB} / \mathrm{CB}$ composites

\begin{tabular}{lcccccc}
\hline Sample & $\operatorname{Tg}\left({ }^{\circ} \mathrm{C}\right)$ & $\operatorname{Tg}_{2}\left({ }^{\circ} \mathrm{C}\right)$ & $\operatorname{Tcc}\left({ }^{\circ} \mathrm{C}\right)$ & $\operatorname{Tm}\left({ }^{\circ} \mathrm{C}\right)$ & $\mathrm{Tm}_{2}\left({ }^{\circ} \mathrm{C}\right)$ & $\mathrm{Tc}\left({ }^{\circ} \mathrm{C}\right)$ \\
\hline $\mathrm{MB}$ & -27.9 & 63.0 & 107.8 & 122.6 & 166.7 & 66.6 \\
$\mathrm{MB}+1 \% \mathrm{CB}$ & -28.3 & 62.8 & 106.5 & 126.3 & 168.3 & 86.3 \\
$\mathrm{MB}+2 \% \mathrm{CB}$ & -28.0 & 62.9 & 106.6 & 125.7 & 168.1 & 86.8 \\
$\mathrm{MB}+4 \% \mathrm{CB}$ & -28.1 & 63.4 & 106.2 & 125.6 & 168.3 & 89.6 \\
\hline
\end{tabular}

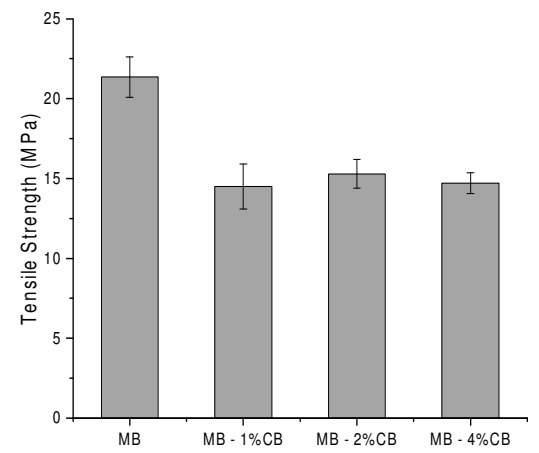

Figure 1: Tensile strength of electroconductive composites

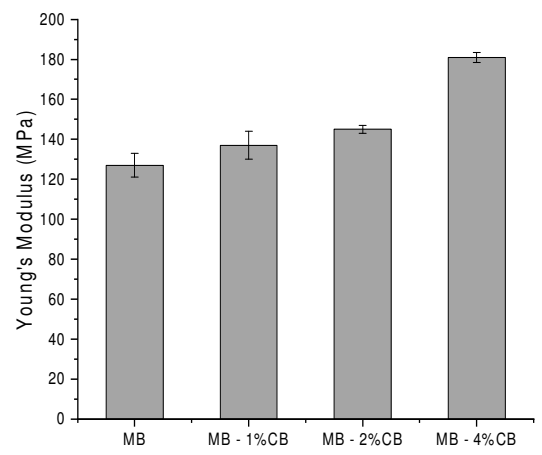

Figure 2: Young's modulus of electroconductive composites



Figure 3: Elongation at break of electroconductive composites

\section{Dielectric relaxation measurements}

The materials in the form of pellets were assessed in terms of their possible dielectric relaxation properties. The results are presented in Figures 4 and 5, in two graphs distinguishing between dispersion (Fig. 4) and loss (Fig. 5). The addition of subsequent amounts of $\mathrm{CB}$ is reflected in the increasing overall value of both real and imaginary parts of dielectric permittivity. Although the increase is not proportional, especially for the sample containing $2 \% \mathrm{CB}$, which was expected to reflect a more significant dielectric character, it can be stated that the discussed dependency is respected.

Although not obvious, a relaxation signal is recorded for the samples containing carbon black at a concentration level not less than $2 \%$. This phenomenon is observed on both the dispersive and the loss curves for the samples containing $2 \%$ and $4 \% \mathrm{CB}$. The respective relaxation frequencies are located around $10 \mathrm{kHz}$ and $35 \mathrm{kHz}$, which is clearly seen on the dielectric curves presented in Figures 4 and 5 . 
KAROL LELUK et al.

Table 2

Resistivity measurements of selected composites

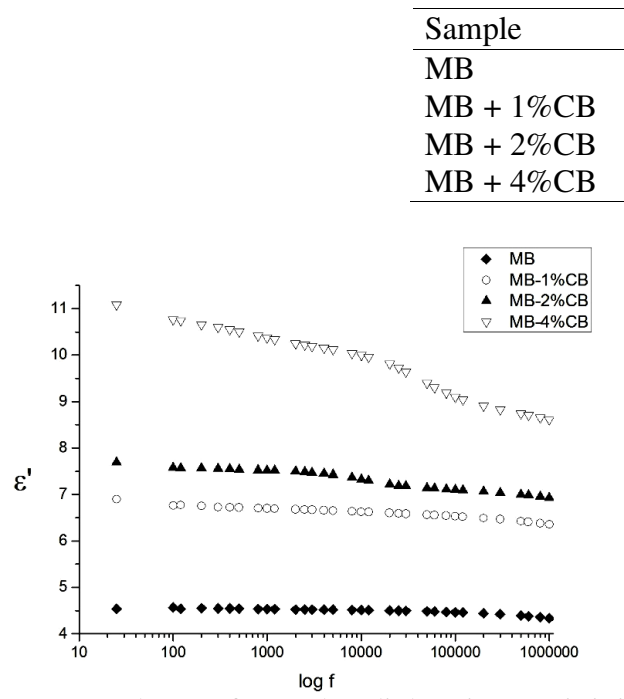

Figure 4: Real part of complex dielectric permittivity measured in the frequency range of $25 \mathrm{~Hz}-1 \mathrm{MHz}$

It has to be noted that, for high frequencies, another absorption curve appears, as may be remarked in Figure 4. Unfortunately, because of instrumental limitations, it was impossible to record the whole second relaxation curve. However, based on the values for the real part of dielectric permittivity measured for the loaded samples at $1 \mathrm{MHz}$, and comparing them to the reference sample (MB) (Fig. 4), there is enough space for an additional dispersion process. On that basis, the increasing values of the imaginary part of dielectric permittivity at $1 \mathrm{MHz}$ can be assumed as a relaxation curve onset.

An interesting fact is the precession of the relaxation frequency from around $10 \mathrm{kHz}$ to $35 \mathrm{kHz}$, when increasing the $\mathrm{CB}$ ratio from $2 \%$ to $4 \%$. The presence of the maximum peak on the loss curve is an indication of the appearance of relaxation, being the result of the discrete structure (the isolation of singular species) of the CB particles formed in the polymer composite. This arrangement, when it comes to a higher filling ratio, may loosen the entanglement of the polymer chains, unlocking additional freedom degrees, thus shifting the relaxation process to higher frequencies.

\section{CONCLUSION}

The present work allowed drawing the following conclusions.
- The addition of 1,2 and 4 wt\% carbon black affects the formation of crystallites in the MB matrix.

- The obtained composites present a low percolation threshold (below the addition of $1 \mathrm{wt} \%$ filler).

- A decrease in the mechanical properties of the developed materials is noticeable, although it does not limit the application of the materials (i.e. in packaging).

- Concentrations of carbon black higher than of $2 \mathrm{wt} \%$ lead to the formation of a relaxation system with at least one discreet relaxation frequency. Increasing the amount of the filler leads to a shift of the relaxation frequency to higher values.

ACKNOWLEDGEMENTS: This work was supported by M-ERA.NET (BIOFOODPACK, "Biocomposite Packaging for Active Preservation of Food"), agreement no.: MERA.NET2/2016/06/2018.

\section{REFERENCES}

1 N. Mateeva, H. Niculescu, J. Schlenoff and L. R. Testardi, J. Appl. Phys., 83, 3111 (1998), https://doi.org/10.1063/1.367119

2 H. K. Chaudhari and D. S. Kelkar, Polym. Int., 42, 380 (1997), https://doi.org/10.1002/(SICI)10970126(199704)42:4<380::AID-PI727>3.0.CO;2-F 
3 H. Wang, S. Yi, X. Pu and C. Yu, ACS Appl. Mater. Interfaces, 7, $9589 \quad$ (2015), https://doi.org/10.1021/acsami.5b01149

4 X. Cheng, T. Yokozeki, M. Yamamoto, H. Wang, L. Wu et al., Compos. Sci. Technol., 144, 160 (2017), https://doi.org/10.1016/j.compscitech.2017.03.030

5 M. Sumita, K. Sakata, S. Asai, K. Miyasaka and H. Nakagawa, Polym. Bull., 25, 265 (1991), https://doi.org/10.1007/BF00310802

6 Z. Zhou, S. Wang and Y. Zhang, J. Appl. Polym. Sci., 102 , 4823

(2006),

https://doi.org/10.1002/app.24722

7 X. Du, Y. Zhang, X. Pan, F. Meng, J. You et al., Compos. Part B Eng., 156, 1 (2019), https://doi.org/10.1016/j.compositesb.2018.08.033

8 Q. Chen, X. Wen, H. Chen, Y. Qi, J. Gong et al., Polym. Adv. Technol., 26, $128 \quad$ (2015), https://doi.org/10.1002/pat.3431

9 J. Yu, N. Wang and X. Ma, Biomacromolecules, 9, 1050 (2008), https://doi.org/10.1021/bm7012857

${ }^{10}$ K. Li, K. Dai, X. Xu, G. Zheng, C. Liu et al., Colloid. Polym. Sci., 291, 2871 (2013), https://doi.org/10.1007/s00396-013-3038-2

11 H. Tsuji, Y. Kawashima, H. Takikawa and S. Tanaka, Polymer, 48, $4213 \quad$ (2007), https://doi.org/10.1016/j.polymer.2007.05.040

12 C.-F. Kuan, H.-C. Kuan, C.-C. M. Ma and C.-H. Chen, J. Phys. Chem. Solids, 69, 1395 (2008), https://doi.org/10.1016/j.jpcs.2007.10.060

13 G. Gorrasi and A. Sorrentino, Polym. Degrad. Stabil., $\quad 98, \quad 963$ (2013), https://doi.org/10.1016/j.polymdegradstab.2013.02.012 14 D. Wu, L. Wu, M. Zhang and Y. Zhao, Polym. Degrad. Stabil., 93, $1577 \quad$ (2008), https://doi.org/10.1016/j.polymdegradstab.2008.05.001 15 Y. Z. Wan, Y. L. Wang, Q. Y. Li and X. H. Dong, J. Appl. Polym. Sci., 80, 367 (2001), https://doi.org/10.1002/1097-

4628(20010418)80:3<367::AID-APP1108>3.0.CO;2$\mathrm{U}$
16 S.-S. Yao, F.-L. Jin, K. Y. Rhee, D. Hui and S.-J. Park, Compos. Part B Eng., 142, 241 (2018), https://doi.org/10.1016/j.compositesb.2017.12.007

17 Y. Gao, O. T. Picot, E. Bilotti and T. Peijs, Eur. $\begin{array}{llll}\text { Polym. } & \text { J., } & \mathbf{8 6}, & 117\end{array}$ https://doi.org/10.1016/j.eurpolymj.2016.10.045

18 B. Yuan, A. Fan, M. Yang, X. Chen, Y. Hu et al., Polym. Degrad. Stabil., 143, 42 (2017), https://doi.org/10.1016/j.polymdegradstab.2017.06.015

19 Y.-S. Jun, J. G. Um, G. Jiang, G. Lui and A. Yu, Compos. Part B Eng., 133, 218 (2018), https://doi.org/10.1016/j.compositesb.2017.09.028

20 A. I. Medalia, Rubber Chem. Technol., 59, 432 (2019), http://doi.org/10.5254/1.3538209

21 Mater-Bi - Biodegradable and Compostable Bioplastics - $\quad$ Novamont, (n.d.), https://www.novamont.com/eng/mater-bi (accessed September 27, 2019)

${ }^{22}$ R. Grujić, D. Vujadinović and D. Savanović, in "Advances in Applications of Industrial Biomaterials", edited by E. Pellicer, D. Nikolic, J. Sort, M. Baró, F. Zivic et al., Springer International Publishing, Cham, 2017, p. 139, https://doi.org/10.1007/978-3-31962767-0_8

${ }^{23}$ Z. Su, Q. Li, Y. Liu, G.-H. Hu and C. Wu, J. Polym. Sci. Part B Polym. Phys., 47, 1971 (2009), https://doi.org/10.1002/polb.21790

${ }_{24}$ X. H. Li, W. H. Guo and C. F. Wu, J. Macromol. Sci. Part B: Phys., 46, 761 (2007), https://doi.org/10.1080/00222340701389027

25 S. Z. B. Qiu, T. Ikehara and T. Nishi, Polymer, 44, $3095 \quad$ (2003), https://doi.org/10.1016/S00323861(03)00216-7

26 A. Iwańczuk and M. Walków, Cellulose Chem. Technol., $\quad 53, \quad 934 \quad$ (2019), https://doi.org/10.35812/CelluloseChemTechnol.2019. 53.91 